\title{
Comparative Analysis of Core Banking Solutions in Serbia
}

UDC: 005.52:336.71(497.11)

005.218

DOI: 10.7595/management.fon.2015.0019

Core banking solutions (CBS) became the main subject of competirion within banking market. This paper describes the architecture of a standard CBS. Discussed here are the solutions of the world's greatest vendors as well as implementation of CBS solutions in Serbia. A comparative analysis of the examined solutions was performed regarding the most sought after features when it comes to the core banking system. Based on results it can be concluded that the complexity of core banking solution depends mostly on client's requirements. The core banking system may contain a wide range of functional areas (modules), but technical features as well as protection systems of these solutions have the most significant impact on their reliability.

Key words: core banking, CBS analysis, core banking solution

\section{Introduction}

Improvement and development of information technologies led to creating new software solutions within the banking area. Modern banking implies the application of information technologies with the aim to improve business and to provide all necessary services to the clients. In that way, the client of the bank is allowed to access and manipulate their accounts online.

Core banking (Centralized Online Real-time Electronic Banking) refers to the services of networked branches that allow to their clients to access their funds and to perform simple transactions from any place. In a broader sense, it refers to the exchange, upgrade and outsourcing core banking system integrated into the package of software applications for processing and posting the transactions, as well as managing the accounting processes. The basis of this system are deposits and loans. In order to ensure their clients these transactions, banks use core banking applications. Every change reflects to the centralized datacenter, which contains all necessary data of clients and their accounts. In order to collect all transactions from individual branches, e.g., EoD (End of the Day) performs at the end of the working day, i.e., COB (Close of Business); at the end of the month goes e.g., EoM (End of Month), and at the end of the year it is e.g., EoY (End of Year).

There are many providers around the world that sell their core banking products to the banks, such are FIS, Temenos, Oracle Financial Services Software, Infosys Technologies, Fiserv, TCS FS, SAP, Polaris and many others. These products are called core banking solutions and some of the operations they provide are recording transactions, maintaining savings books, calculating interest rates for loans and deposits, keeping the customer's data, balance of payments, etc. Shortly, the CBS (Core Banking Solution) refers to connecting the branches, which allows clients to manipulate their funds, independently of the branch in which these are opened.

The aim of this paper is to examine CBS solutions available on the domestic market and to analyze their basic features. In the remainder of this paper, after a preview of the world's famous practices in core banking system, a short comparative analysis of CBS solutions of the most famous vendors on the territory of Serbia will be conducted. For this purpose three most famous CBS solutions will be ranked based on certain features. It should be taken into consideration that needs of each client of a particular vendor may be significantly different, which affects the diversity of the solution's features. 


\section{Literature review}

The first core banking system emerged in 1970's and provided the basic functionality for the core banking transactions. Later, in 1980's, solutions were developed based on packages, with the product-orientation, but without a capacity to process a large amount of data. The first systems that were client-oriented were significantly opened, flexible and scalable with the convergence of digital channels and they appeared in 1990's. The last decades CBS solutions tend to increase the mobility in terms of providing services to the clients, but with an aim to achieve real time processing and to allow multichannel integration .

A standard contemporary CBS system can contain many modules such as deposits, loans, cards, etc., and each module is individually tested as a separate sub-project. These modules make a CBS program, which presents the collection of unrelated projects, which are managed at the same time and which are independent of each other. The program is divided into two categories :

- The first category consists of a discrete program that presents the main cluster of the organization and the structure of project management.

- The second category consists of a continuous program based on customer's usage which includes the organization and the structure of project management .

The CBS system is a very important software solution for commercial banks. As the complexity of these systems grows, software testing becomes more complex and difficult. It is necessary to determine which criteria such a solution must meet and to choose a model which will include all necessary correlations among the selected criteria. During testing the software it is important to define a method of determining the quality of software testing. Evaluation of the testing software quality can be determined by using the traditional and frequently used criteria :

- Test case coverage rate - number of function points included into case compared to total number of points;

- Case tested rate - number of test cases compared to total number of cases;

- Testing hit rate - number of detected problems compared to total number of cases;

- Average case execution time - average time spent by each test case execution;

- State ratio - number of test cases compared to total number of cases.

Applying this method for evaluation of software testing , testing of the following five modules as individual sub-projects: deposits, loans, cards, RTGS (Real Time Gross Settlement), customer management was performed.

Even though banks are effective financial units, they enter fierce competition when it comes to attracting new clients and retaining the existing ones. This is becoming more and more challenging but using the new technologies and the so-called "concentrated banking package" there is a possibility to provide services to the clients by fulfilling their spontaneous requests. In fact, the establishment of an integrated banking system becomes a necessity, not a choice. Numerous studies have pointed to the fact that banks recklessly increase their benefits by increasing the number of their most important customers making them fully satisfied with their services. On the other hand, customers are able to compare services of certain banks and to join the one that best suits their needs. Security, money transfer speed, simple use, reliability, and privacy issues are some of the factors that influence the customer to choose the bank .

in his research noted the biggest obstacles when it comes to the use of core banking system on the example of agricultural bank. Ferguson's model served as a visual framework for the research. The authors of this paper conclude that the most commonly perceived obstacles are related to organization, management, finances and technical and technological issues. The author state four hypotheses related to the influence of the above-mentioned obstacles on effective performance and development of the core banking system. Research has shown that all of these hypotheses were confirmed. According to the research, the biggest impact on effectiveness is made the organizational issues, then follow technology, management and finances, respectively.

As the financial systems are the main targets of hackers, security becomes a challenge for e-banking. Currently popular and increasingly applied environment is the cloud that is suitable for the implementation of personalized security mechanisms for large companies. Several authors suggest user-defined rules that raise the security of e-payment on a higher level. 
Even though there are many solutions that are used to minimize the fraud risk and to create a better defense mechanism for online transactions, none of these solutions can provide a long-term full protection whereas new ways of abuse are being developed. This leads to constant improvement of these mechanisms. Flask architecture presented in the paper is part of the National Institute for Standards and Technologies (NIST) and is strengthened with mandatory approach and competitive control with an aim to meet the requests for an extensive processing of banking transactions in a short term.

When it comes to cards security, it should be noted that cards should work with specific devices (e.g. card must be active for online banking and Internet transactions must be conducted through IP range of the company). Some accounts work on the principle of sending an SMS with the code for transaction confirmation. If the user does not enter the confirmation code in a certain time interval, the ransaction is aborted. It is also important to confirm transactions by fax or e-mail, otherwise a transaction will be automatically cancelled in a certain period of time. One of the most commonly used protection methods is a two-factor protection concept (subtype of multifactor protection) that implies two levels of authentication for higher security. The most common examples are raising money from the ATM where the client is required to possess a card and matching the PIN code or using e-banking services via tokens where, in addition to owning a token, it requires also a knowledge of access code.

When it comes to practices that are applied in certain countries of Europe and that are related to the core banking system, the example of the use of these systems in the Czech Republic should be mentioned. In 2010 an independent project named RCBS Calculator (retail core banking services calculator) was initiated in the Czech Republic. The purpose of this project was to compare banking fees of different accounts based on requested services (account administration, cash, money transfer, etc.) and price. The calculator works like this: the client enters his pattern of use and the calculator suggests the least expensive option on the Czech market. This expert system compares the expenses of the account and suggests the products with the lowest expenses. Knowledge database of the Calculator application contains tariff information of 12 banks, which represents more than $98 \%$ of RCBS market of the Czech Republic and their 45 accounts.

The Calculator works as follows - the client fills in the form that contains 52 questions about using certain services. Then, the application performs the calculation of the client's monthly expenses in terms of RCBS and other banking services. Questions are divided into logical sections: Accounts, Reports, Cards, Ebanking, Direct payments, Standing orders, Authorization for liquidation, Cash, Other services.

After processing the completed questionnaire, the Calculator organizes the list of banking offers sorted from the more to less favorable, according to the type of chosen service.

These calculators are still in infancy in Serbia and currently they are organized through simple models that facilitate a review of banking services in Serbia. In this way, potential customers can check current offer without going to the bank and choose the one that best suits their needs.

\section{CBS advantages}

The application of ICT in banking overcomes obsolete communication methods with their clients. First, this was the one-way communication in the form of delivery of basic information on the bank's website for its existing and future customers, then this became a two-way communication in order to respond to the customer's e-mails, but from the marketing aspect. Finally, presenting the concept of e-banking has meant a progress in the communication between the bank and the client because this way the client can perform banking transactions on the Internet from anywhere, without going to the bank branch office.

To make it easier for customers to access their accounts and to simplify banking transactions, with the assistance of CBS banks provide the following services:

- determining the balance - debit or credit entries on the account;

- access and review of client's accounts;

- records of all transactions;

- cash payments from the client's cash account;

- Ioan payments on client's account;

- incoming cash payment on the account;

- account statements from the previous day; 
- update information;

- ordering checks;

- money transfer from one account to another (if the owner of the other account is a client of CBS branch office);

- payment of predefined accounts;

- Ability to use ATM because it is networked with CBS platform, and all changes on the account are visible to the customer.

\section{The architecture of CBS}

The basis of any CBS system is a group of linked servers that present a datacenter. The datacenter stores all data of clients and their accounts, as well as all changes that are performed on them. All these changes are visible to all branches, as well as to clients themselves, whether they access their accounts via mobile phone, e-banking account or ATM. The architecture of average CBS system is presented in Figure 1.

Such systems should have a good protection system and an organized disaster recovery system. The CBS system must also satisfy legal regulations, given that the CBS system works with sensitive data, so communication channels must be well protected. In 2013 the National Bank of Serbia adopted the law on minimum standards of IT systems management in financial institutions in order to establish foundations on which an IT system should be based on, as well as directions of its functioning in the sense of reducing risk and an overall standardization, . Many companies develop security systems for the CBS, such as Odyssey Snorkel of the Odyssey Technologies company that has a strong double authentication, and provides channels security and access control with a digital signature and thereby preserves transactions integrity. This security system was implemented in the HDFC bank in India and in Sharjah Islamic Bank in United Arab Emirates.

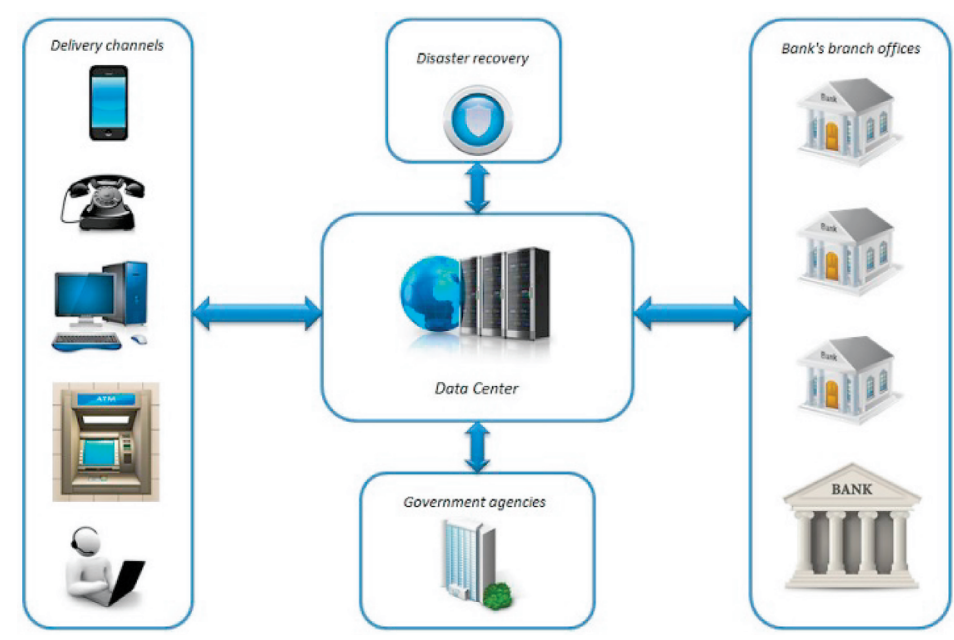

Figure 1:The example of CBS architecture

\section{Survey of CBS Solutions}

Although there are numerous corporations worldwide that develop software solutions that facilitate work to the banks, in this paper we will describe CBS software solutions developed by companies:

- FIS (Fidelity National Information Services - FNIS);

- Temenos;

- Oracle Financial Services Software;

- Pexim;

- Antegra;

- Asseco. 
Given that they are considered as vendors for the most popular core banking applications. It should be mentioned that Temenos is a vendor that provides its solutions also to the Serbian banking market. It is known that Hypo-Alpe-Adria Bank Serbia uses the Temenos T24 core banking solution.

In the following chapters a little more will be said about the companies that develop software solutions to assist banks in order to provide the necessary services to customers in real time. A schematic review of the client-vendor relationship is shown in Figure 2.

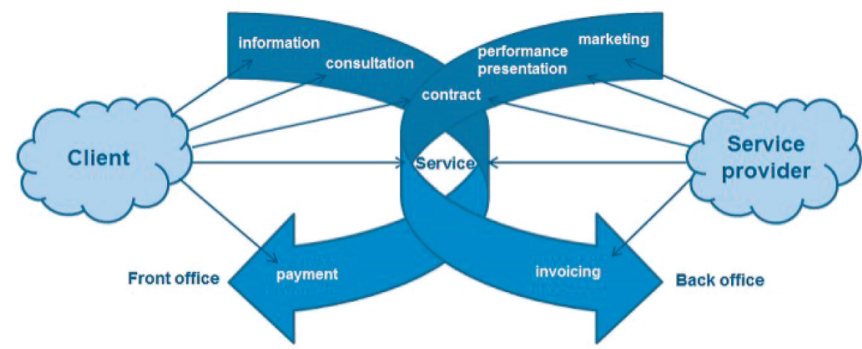

Figure 2: Scheme of front-office and back-office

The Front-office implies a business unit of the company that provides real-time direct support to their customers, while the back-office is an internal part that does not have direct communication with customers.

In the following text, in addition to the world-known providers and their solutions, products of local and the most abundant providers used by the companies in Serbia will also be described.

\subsection{FIS}

The FIS Company develops banking and financial software solutions for over 14.000 financial institutions in over 90 countries all over the world. Products of this company are: Corebank, Systematics (Alltel), FIS Profile (Sanchez Profile/Anyware), Kordoba, Aurum, ALLprofits, MiSER (US community bank system), Horizon, ACBS (Advanced Commercial Banking System), IBS (Integrated Banking Services). Features for end-users are grouped in the following modules:

- Basic processing;

- Debit and electronic processing;

- Credit solutions;

- Deposit automation;

- Multichannel delivery;

- Safe cash management;

- Fraud management;

- Loyalty and rewarding program;

- Currency processing;

- Electronic bill payment;

- Maintenance service.

The Corebank Software is a client-oriented solution that works in a real time and provides support to banks in a way of deposits, loans and payments. It is based on the IBM model FSDM (Information Framework Financial Services Data Model). This software offers a number of possibilities - the infrastructure of a financial institution, building products, client management and client reviews, account administration, payments, information management.

Systematics is a solution that allows reporting besides managing deposits and loans. It is a multilingual application which is suitable for organizations regardless of their structure, size or location. The possibilities that this software offers are bill payments, an advanced credit system, treasury automation, check inventory, receivables, customer service management, financial system management, integrated monetary control, savings, and real estates. 


\subsection{Temenos}

Temenos is a Swiss company which has over 300 clients all over the world, and its products are implemented in over 100 countries. Established in 1993, this company offers the following products: TEMENOS T24, TEMENOS CoreBanking TCB, T24 MCB (T24 for microfinance and general banking).

These solutions include the following functionalities:

- Corporate sector - commercial lending, overdrafts, commercial transactions, reminders, debt collection, accounts, guarantees, leasing;

- Trading in securities - money market, foreign exchange, securities, futures and options (financial derivatives):

- Retail sector - savings, current accounts, savings and deposit accounts, overdrafts, checks, credit cards, mortgage loans, revolving loans, investment funds;

- Private Banking - Securities and portfolio management clients, business introductions;

- Basic Operations - CRM (Customer Relationship Management), market risk, credit risk, accounting and general ledger, document management, profitability, payments, nostro reconciliation, business flow;.

- Alternative channels - Internet, call center, other e-channels.

In addition to the above, Temenos also offers teller applications, funds transfer, savings accounts, checks and credit cards management as well as ATM server processing. The temenos CBS solution represents a scalable banking application for the retail area.

\subsection{Oracle FSS}

Oracle covers the market of both corporate and retail sectors, then investment banking (funds, cash management, securities trading, payments, lending, asset management, entrepreneurship and business risk analysis). Oracle has a product called FLEXCUBE, which is an aggregation of banking solutions. This solution includes automated teller operations, signature verification and monitoring outstanding receivables.

\subsection{Pexim}

Pexim provides software solutions in the areas of: CBS, e-solutions, business intelligence, professional services, advanced infrastructure services, e-government, with an emphasis on the development of vertical banking solutions. In addition to core banking services, the company's solutions also include payments, credit cards managing, Internet banking, mobile banking, banking DWH (data warehouse), risk management, performance management and CRM.

Pexim Universal Banking (PUB) 2000 is an integrated banking application designed to work with corporate and retail customers. Their modules are:

- Customers information;

- Account administration;

- Payment services;

- Deposits;

- Loans;

- Credit cards;

- General ledgers;

- Support management applications;

- Shares and stock.

Pexim CMS solutions provide management of domestic and foreign credit cards (MasterCard, VISA, DINA, etc.), online and offline data sharing, ATM and POS payment terminals management, Internet and mobile banking.

Banks that use PEXIM solutions are Agrobanka, Credit Agricole, Banca Intesa, the National Bank of Serbia, Čačanska Bank, OTP Bank, Continental Bank Novi Sad, Serbian bank, Credy Bank, ProCredit Bank, Eurobank EFG, UniCredit Bank, JUBMES Bank, Universal Bank, Commercial Bank, Volksbank. 


\subsection{Antegra}

Antegra is a company specialized in the development of banking solutions. As a member of Asseco Group, it supplies the territory of Serbia, Montenegro, Macedonia and Bosnia and Herzegovina with its solutions. The key functionalities of Antegra Bi Core system are:

- System administration;

- Retail banking (savings, current accounts, loans, nostro payments, etc.) ;

- Corporate banking (loans and deposits, current accounts, securities, foreign payments, check clearing) ;

- Bl card;

- Reporting;

- Current assets;

- Shareholder Book;

- Connection with external environment;

- E-banking.

This software also enables the presentation of paper documents in electronic form (signature and images), as well as the ability to optimize the input of operational data in accordance with the requirements of the bank, and it is also easy to use in terms of settings that are understandable to the user.

Banks that use Antegra solutions are AIK Bank, NLB Bank, Opportunity Bank, Piraeus Bank, Commercial Bank, Raiffeisen Bank, Serbian bank, Volksbank.

\subsection{Asseco}

Asseco SEE (Asseco South Eastern Europe) is an IT company that is engaged in producing and implementing its own software solutions to the financial sector and banking, telecommunications, public sector, administration and telecom. It was created by merging of the three companies: PEXIM, Antegra and PEXIM Cardinfo. The three most popular products of the company are: ASEBA PUB 2000, ASEBA bApO and ASEBA BPS.

ASEBA PUB 2000 is an integrated banking application for corporate and retail banking. The key features and benefits of this software solution for document management in banks are:

- Data integrity;

- Compliance with legislation, procedures of the National Bank of Serbia, as well as international standards in banking and document management business;

- The Audit security of archives material;

- Automation and optimization of business processes;

- Significant reduction in operating costs while increasing efficiency;

- More effective business decisions based on "real time" information.

The application architecture is based on a structural and modular model with layered client-server platform with independent modules that provide a simple modification of business processes. The main modules of this system are:

- Information about the client (can be used for direct marketing or customer analysis) ;

- Account services (administration, debit, checks, bank accounts, paying bills, recording activities) ;

- Payment services (ability to pay in local and foreign currency) ;

- Deposits;

- Loans;

- Retail banking (cash, checks, transfer funds, loans, savings level of services, currency exchange, electronic signature, etc.) ;

- Cards;

- General ledger ;

- Application management support ;

- Shares and shareholders books. 
Banks that use ASEBA PUB solution are: Banca Intesa, Jubmes Bank, Commercial Bank, OTP Bank, NLB Bank, Credit Agricole, KBC Bank, Universal Bank, ProCredit Bank, Marfin Bank, Čačanska Bank, Privredna Bank, Postal Savings Bank, Societe Generale.

ASEBA $b A p O$ is an integrated banking solution that encompasses: loans, deposits, payment systems, cards, general ledger. Some of the features are:

- "Real-time" transactions;

- Current accounts;

- Securities trading;

- Accounting;

- Reporting.

Customer benefits are reflected through the implementation of integrated financial applications whose solutions are scalable and adaptable for use in commercial banks. It is a system that works in real time and that in addition to the efficiency, flexibility and effectiveness, provides reliable security. The user interface is customizable to users and provides a range of functionality across different modules. From the technical point of view, this solution offers the possibility of improving business processes and modification of the same, without the need for modification of the application.

Banks that use ASEBA bApO solution are: Raiffeisen Bank, Piraeus Bank, AlK Bank, Serbian bank, Opportunity Bank, Moskovska Bank, Postal Savings Bank, Development Bank of Vojvodina, Volksbank, Alpha Bank.

ASEBA BPS (Banking Process Suite) is a solution for corporate banking that is used to automate business processes and includes the following modules:

- Automation of account opening;

- Automation of lending;

- Automation of the process of documenting the flow of foreign exchange;

- Deposit management;

- Cards management;

- Automation of required reports;

- Automation of board meetings;

- Control of inputs (processing of payment orders, checks or POS papers from branches to the central office) ;

- Automation of payment ;

- Savings accounts opening;

- Physical archiving.

This solution provides data integrity, simplicity, integrity of archiving, data centralization, data availability and their safety, easy troublespotting of bottlenecks and their elimination.

This solution is used in the following institutions: DDOR insurance, Eurobank EFG, Findomestic bank, Commercial bank, Postal Savings Bank, Societe Generale.

\section{Conceptual framework}

Usually, a banking institution conducts business with retail and small business customers. The core of banking business basically is depositing and money lending, hence these services are available across ATMs, e-banking and branches .

The basic functionality of the CBS solution is operating the account by user which is opened in one branch, but is available in another branch. Modern CBS solution refers to providing the following functionalities:

- Retail and corporate banking;

- Account administration;

- Domestic and international payments;

- Deposits;

- Loans;

- Cards; 
- Accounting;

- Shareholding;

- Reporting;

- Internet banking;

- Mobile banking;

- AML (Anti-money laundering)

- Trade finance;

- Online General Ledger;

- Collection and clearing;

- Collateral management;

- Limits management;

- Virtual exchange office, etc.

\section{Comparative analysis of core banking solutions in Serbia}

The analysis was conducted based on the available data related to the usage of CBS solutions. It should be mentioned that the presented solutions are not publicly available and that the right to use these solutions belongs only to exclusive clients of the mentioned vendors. Bearing this in mind, and for the purpose of this paper, characteristics of the mentioned banking software were presented based on available publications and specifications that are at the disposal of the public and can be found on official websites of vendors , . All other data are confidential. The study is based on formal characteristics and comparison of banking software solutions made based on them.

It should be noted that although the Asseco company was created by combining Pexim, Antegra and PEXIM Cardinfo, many banks in Serbia are still using PEXIM and Antegra solutions. It is important to mention that the vendor adapts its system to the specific needs of the client.

Table 1: Comparative analysis of the CBS solutions in Serbia

\begin{tabular}{|r|c|c|c|}
\hline & Pexim & Antegra & ASEBA \\
\hline Retail banking & $\mathrm{X}$ & $\mathrm{X}$ & $\mathrm{X}$ \\
\hline Corporate banking & $\mathrm{X}$ & $\mathrm{X}$ & $\mathrm{X}$ \\
\hline Account administration & $\mathrm{X}$ & - & $\mathrm{X}$ \\
\hline Payment services & $\mathrm{X}$ & $\mathrm{X}$ & $\mathrm{X}$ \\
\hline Deposits & $\mathrm{X}$ & $\mathrm{X}$ & $\mathrm{X}$ \\
\hline Loans & $\mathrm{X}$ & $\mathrm{X}$ & $\mathrm{X}$ \\
\hline Cards & $\mathrm{X}$ & $\mathrm{X}$ & - \\
\hline Accounting & $\mathrm{X}$ & - & $\mathrm{X}$ \\
\hline Shareholding & $\mathrm{X}$ & $\mathrm{X}$ & - \\
\hline Reporting & - & $\mathrm{X}$ & $\mathrm{X}$ \\
\hline SWIFT & $\mathrm{X}$ & $\mathrm{X}$ & $\mathrm{X}$ \\
\hline Einancial derivatives & - & $\mathrm{X}$ & $\mathrm{X}$ \\
\hline E-banking & - & $\mathrm{X}$ & - \\
\hline Access to the external environment & - & $\mathrm{X}$ & $\mathrm{X}$ \\
\hline AML (Anti-money laundering) & - & - & $\mathrm{X}$ \\
\hline
\end{tabular}

Table 1 shows some of the known characteristics of the mentioned core banking software solutions. Since the main sources of information are specifications provided by the vendors themselves, comparison of modules, e.g., functionality, is performed for each individual solution.

From all presented it is clear that Antegra offers a number of features to its customers, which are more specifically shown in Figure 3, (the percentage represents the CBS solution characteristics fulfillment). Out 
of the total number of criteria presented, Antegra and ASEBA BAPO meet even $75 \%$ (12 out of 16 surveyed characteristics), while PEXIM meets $62.50 \%$ (10 out of 16 surveyed characteristics).

Since it is not enough to focus only on the characteristics and modules covered by the CBS solution (they can vary from one solution to another), the technical background of the CBS solution must be taken into consideration. For this purpose it is necessary to examine the following: application technology, database, API access, user interface, security issues, multilingualism and platform type.

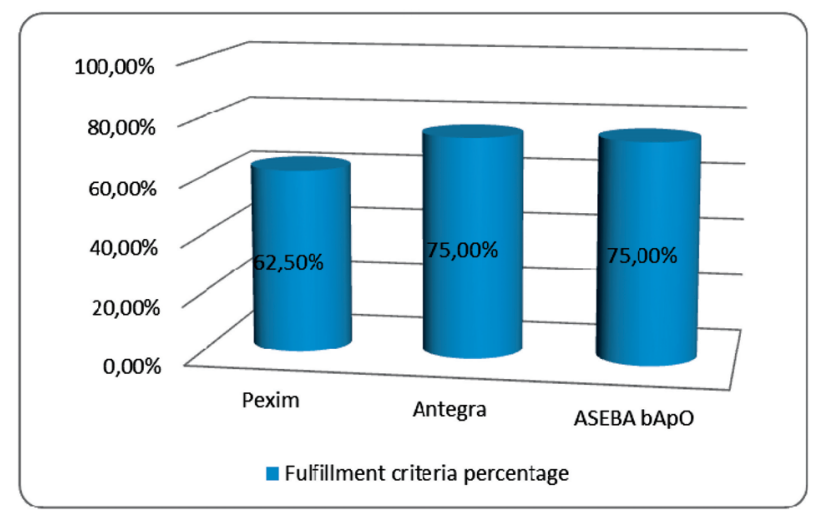

Figure 3: Graphical representation of fulfillment criteria percentage

ASEBA BAPO and Antegra work in Java, $\mathrm{C}$ and Oracle technologies, while PEXIM works only on .NET technology. All three solutions support multilingualism and have the opportunity to work on the Windows platform, while Antegra and ASEBA can work on other operating systems as well. Antegra and ASEBA are web applications, while PEXIM is a desktop application. All three solutions have their own security systems.

As a software solution that works with sensitive data about customers and their funds, it is important that it has a good security system, a good DRP - Disaster Recovery Plan, as well as a recovery process in the case of the system failure. The configuration of the system itself is a very important issue and before launching such a system on the market, it is important that the solution be adequately extensively tested on all covered modules. That reduces the chance to slip a fault which can make a problem. Companies that develop such solutions have specialized teams (Test Management Team), which are engaged in software testing based on pre-defined test scenarios. We should not ignore the test by the client, the so-called UAT test (User Acceptance Test), where the client checks whether the solution is developed on the basis of their needs.

\section{Conslusion}

By examining the CBS system in Serbia it was concluded that there are three dominating solutions in this area - Pexim, Antegra and ASEBA. Our intention was to find out which are the most frequent characteristics that CBS solutions should fulfill and based on these findings the list of characteristics, e.i., modules that the analyzed solutions should meet were created.

It is difficult to say which of the analyzed technologies is the best, or the most reliable. It is well known that Assecco company was formed by merging the companies Pexim and Antegra. However, Pexim and Antegra software is still applicable in the banking system of Serbia and beyond.

\footnotetext{
2 Access only via SWIFT, RTGS, CARD processors
} 
The aim of this paper was to get familiar with the basic concept of CBS as a new mechanism that raises banking onto a higher level.

This paper describes the ways of banking software testing as well. It is important to note that customers' needs evolve along with technology development. This leads to introducing new, personalized solutions that will satisfy their needs.

This leaves room for the new papers and detailed research. Given the lack of information availability related to CBS solutions, it can be concluded that in a few years, maybe decades, we will be able to get answers regarding precise architecture and functionality of these complex systems.

However, based on incomplete information that is available, this paper presented the comparative analysis of banking software solutions in Serbia. The overall conclusion is that Antegra and ASEBA bApO presented the highest percentage $(75 \%)$ of total number of examined modules that should be covered by an average CBS system. We should also take into consideration the simplicity of the usage of these solutions, as well as adaptability to the new users. These are data that are not widely available, hence they were not the subject of this paper.

It should be noted that there are differences between CBS solutions used abroad and the ones used in Serbia in a way of different calculation of interest rate amount, different exchange rates, etc. Nevertheless, the CBS solutions differ from provider to provider, but also, there is a difference in a client's (bank's) requirements. There are many factors affecting a final CBS product, so it is difficult to tell in which way it can be improved due to different client's needs. As it was presented in Table 1, some of functionalities are not provided by all mentioned CBS solutions, but it does not mean that they cannot be developed and/or integrated within a particular CBS. The use of new ICT technologies with respect to the hurried and busy life of an average user of banking services, as well as the advantages of mobile technologies and services, represent improvement by themselves. The future development trend may include NFC (Near Field Communication) technology which represents the basis of use of the "wave-to-pay" payment systems which can be integrated into the personal device such as mobile phone.

\section{REFERENCES}

[1] Antegra. (2015). Retrieved 2015, from http://www.inntron.com/banksys/antegra.htm

[2] Asseco. (2014). Retrieved 2015, from Asseco: https://asseco.com/

[3] Capgemini. (2013). Core banking transformation measuring the value. Preuzeto May 2014 sa http://www.capgemini.com/: http://www.capgemini.com/resource-fileaccess/resource/pdf/core_banking_transformation_measuring_the_value.pdf

[4] Entezar, E. (2011). Analysis and Ranking the Obstacles and Challenges in performing and reforming core banking based on Ferguson Model (Case Study: Agricultural Bank). Procedia - Social and Behavioral Sciences 25, $375-383$.

[5] Fu-Qing, Y. (2005). Thinking on the development of software engineering technology. Journal of Software, 1-7.

[6] Hamidi, N., Mahdi Rahimi, M., Nafarieh, A., Hamidi, A., \& Robertson, B. (2013). Personalized Security Approaches in E-Banking Employing Flask Architecture over Cloud Environment. Procedia Computer Science 21, $18-24$.

[7] Hedvicaková, M., \& Soukal, I. (2012). Retail core banking services costs optimization. Procedia Technology $1,177-182$.

[8] India Post. (2013). Core Banking Solution (CBS) - IT Modernization Project. Retrieved 2015, from India Post - Ministry of Communication and Information Technology: http://www.indiapost.gov.in/it_modernisation cm/Core\%20Banking\%20Solution FAQs.pdf

[9] Kolodinsky, J., Hogarth, J., \& Hilgert, M. (2004). The adoption of electronic banking technologies by US consumers. Emerald Group Publishing Limited.

[10] Laforet, S., \& Li, X. (2005). Consumers' Attitudes Towards Online And Mobile Banking In China. International Journal Of Bank Marketing, 362-380.

[11] BIBLIOGRAPHY Manjushree, S. (2014). AN IMPLEMENTATION OF CORE BANKING SOLUTION WITH SPECIAL REFERENCE TO SBI, SHIVAMOGGA. Sai Om Journal of Commerce \& Management

[12] Meilong, X., Congdong, L., Qiong, X., \& Konglai, Z. (2009). Research on executive performance of financial software programme. Journal of Xidian University (Social Science Edition), 35-39. 
[13] Pantović, V. (2013). MINIMALNI STANDARDI UPRAVLJANJA INFORMACIONIM SISTEMOM FINANSIJSKE INSTITUCIJE. INFOTECH.

[14] Pexim. (2015). Retrieved 2015, from http://www.inntron.com/banksys/pexim.htm

[15] Pinto, J. (2007). Project Management: Achieving Competitive Advantage. Pearson education international.

[16] Službeni glasnik, R. (2013). Minimalni standardi upravljanja IT sistemom.

[17] Soukal, I., \& Hedvicaková, M. (2011). Retail core banking services e-banking client cluster identification. Procedia Computer Science 3, 1205-1210.

[18] Zhang, W., \& Zhu, F. (2012). An Evaluation Model of Software Testing Management in Core Banking System Programme. Physics Procedia 25, 1857 - 1862.

Receieved: May 2015. Accepted: July 2015.

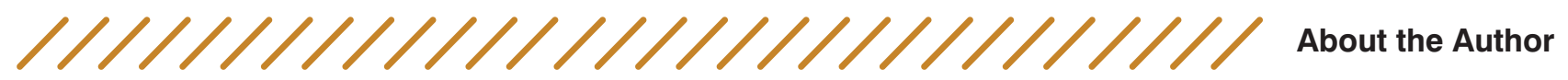

Marija Kreća

University of Belgrade, Faculty of Organizational Sciences, Serbia marija.kreca@gmail.com

Marija Kreća(1988), is a third year PhD student at the Department of E-business at the Faculty of Organizational Sciences, University of Belgrade. She works with the Hewlett Packard Ltd. company as Release and Testing Specialist. Her research interests are: E-banking, E-government, E-education, Internet Technologies, Mobile Technologies

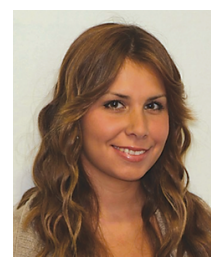

Dušan Barać

University of Belgrade, Faculty of Organizational Sciences, Serbia dusan@elab.rs

Dušan Barać (1983) is an assistant professor at the Faculty of Organizational Sciences, University of Belgrade. His research interests are: Internet Technologies, E-business, M-business, Internet of Things, E-education, E-banking.

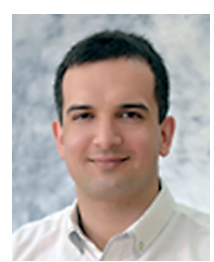

